American Journal of Applied Sciences 6 (2): 285-289, 2009

ISSN 1546-9239

(C) 2009 Science Publications

\title{
A Minimizing Cost of Transport Gabage in Nonsung District Nakhon Ratchasima Province, Thailand
}

\author{
P. Littidej and S. Suttayamully \\ School of Transportation Engineering, \\ Suranaree University of Technology, Thailand, 30000
}

\begin{abstract}
The objective this research for estimate minimum cost of gabage from its sources to disposal sites in Nonsung District Nakhon Ratchasima Province, Thailand. By using genetic algorithms run in microsoft excel add-ins find the minimum cost and appropriate waste allocation. The distance applied in the simulation was displacement between two points not the true distance along the route. It was found from the study that the factors affecting the pattern of the hauling system and waste allocation were number of sources and waste quantities produced, number and capacity of transfer stations and disposal sites and hauling cost from different points.
\end{abstract}

Key words: Minimizing cost, transport gabage, genetic algorithms in excel

\section{INTRODUCTION}

The activity that happen in the every day life of majority human often is born remainder inventory uses and don't be required and touch abandon the garbage which will cause a problem builds the environment goes up a lot of such as the source of water is born contaminatedding, be born the smell doesn't desire, be disease birthplace differs thus for problem prevention that is born from the garbage are effective affect the environment, solid waste management appropriately

then should bring to consider in the remedy systematically, by consider topmost advantage of the engineering, sanitation, economics, social and the environment.

The saving collects and solid waste shipping are pillar element at must bring to consider in solid waste management because the step that must pay for expenses about 80 percentages of expenses in all solid waste management (Hagerty et al., 1978). Which in the saving carries the garbage does will by the arrangement seeks a car picks to carry go to serve pick carry area garbage source differs such as residence section, business quarter, industrial factory section, agriculture section, etc., (Udomsak, 2004).

Thereafter then induce still the station transfers the garbage for collects and the transportation go to disposal site. The garbage or might induce still the place eradicates the garbage directly very grasping is garbage can do many the way such as doing fertilizer burning down burying covers up and the forcing down filters outdoor or recycle which garbage shipping for be born top most necessary efficiency will tomust lead economics pillar comes in to consider share in shipping format for expenses in the shipping is lowland expenses most and can plan in the distribution sends garbage quantity from the source goes to disposal site transfer or that can eradicate appropriately and help give can decide in station choosing transfers the garbage or the place eradicates the garbage cooperates standard of the environment of area state form that get as well. This research will emphasize analysis of mathematics model for seek minimum expenses in garbage shipping from the source goes to still the place eradicates, by this model has used the principle researches to operate that pertaining to linear straight mathematics comes to help solve a problem in sending.

\section{MATHEMATICAL FORMULATION}

The mathematics model in this research, be the model that consider garbage shipping from the source goes to disposal site (Fig. 1) which might have or don't have the station transfers the garbage in shipping system all right.

Objective function: Minimize

$$
\mathrm{Z}=\sum_{\mathrm{i}=1}^{\mathrm{N}} \sum_{\mathrm{j}=1}^{\mathrm{J}} \mathrm{C}_{\mathrm{ij}} \mathrm{X}_{\mathrm{ij}}+\sum_{\mathrm{i}=1}^{\mathrm{N}} \sum_{\mathrm{k}=1}^{\mathrm{K}} \mathrm{C}_{\mathrm{ik}} \mathrm{X}_{\mathrm{ik}}+\sum_{\mathrm{j}=1}^{\mathrm{J}} \sum_{\mathrm{k}=1}^{\mathrm{K}} \mathrm{C}_{\mathrm{jk}} \mathrm{X}_{\mathrm{jk}}+\sum_{\mathrm{j}=1}^{\mathrm{J}} \mathrm{F}_{\mathrm{j}} \sum_{\mathrm{i}=1}^{\mathrm{N}} \mathrm{X}_{\mathrm{ij}}
$$

Subject to constraints

Corresponding Author: P. Littidej, School of Transportation Engineering, Suranaree University of Technology, Nakhon Ratchasima, 30000, Thailand Tel: +66-85-8587011 


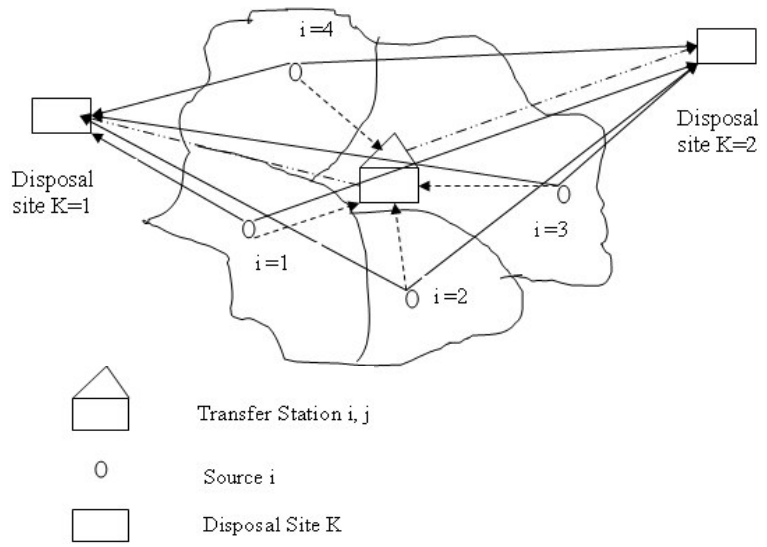

Fig. 1: Mathematical formulation for minimizing cost of transport gabage

$$
\begin{aligned}
& \sum_{j=1}^{J} X_{i j}+\sum_{k=1}^{K} X_{i k}=W_{i} \text { for } i \\
& \sum_{i=1}^{N} X_{i j} \leq B_{j} \quad \text { for } j \\
& X_{i j} \geq 0 \\
& X_{i k} \geq 0 \\
& X_{j k} \geq 0 \text { for } i, j, k \\
& \sum_{i=1}^{N} X_{i k}+\sum_{j=1}^{J} X_{j k} \leq B_{k} \quad \text { for } k \\
& P_{j} \sum_{i=1}^{N} X_{i j}-\sum_{k=1}^{K} X_{j k}=0 \quad \text { for } j
\end{aligned}
$$

Let:

$X_{\mathrm{ij}}=$ Garbage quantity that the transportation from the source $\mathrm{i}$ go to still the station transfers the garbage $\mathrm{j}$ unit/time

$\mathrm{X}_{\mathrm{jk}}=$ Garbage quantity that the transportation from the station transfers the garbage $\mathrm{j}$ go to the disposal site $\mathrm{k}$ unit/time

$\mathrm{C}_{\mathrm{ij}}=$ Cost per unit garbage in garbage shipping from the source $\mathrm{i}$ go to the station transfers the garbage $\mathrm{j}$

$\mathrm{C}_{\mathrm{jk}}=$ Cost per unit garbage in garbage shipping from the station transfers the garbage $\mathrm{j}$ go to disposal site $\mathrm{k}$

$F_{j}=$ Cost per unit garbage in garbage shipping from the station transfers the garbage $\mathrm{j}$ (Construction+Operation)
$\mathrm{W}_{\mathrm{i}}=$ All garbage quantity that is born from the source i unit/time

$\mathrm{B}_{\mathrm{j}}=$ Garbage quantity that the station transfers the garbage $\mathrm{j}$ can accept unit/time

$\mathrm{B}_{\mathrm{k}}=$ Garbage quantity that the disposal site the garbage $\mathrm{k}$ can accept unit/time

$\mathrm{P}_{\mathrm{j}}=$ Fraction of garbage quantity after change the station on the for way induce at the disposal site the garbage $\mathrm{k}$

$\mathrm{P}_{\mathrm{j}}=1$ if the station on the way be the station transfers the garbage

$\mathrm{P}_{\mathrm{j}}=0.2$ if the station on the way be incinerator

$\mathrm{N}=$ Number of source $\mathrm{i}$

$\mathrm{J}=$ Number of the station transfers the garbage $\mathrm{j}$

$\mathrm{K}=$ Number of the disposal site $\mathrm{k}$

\section{THE GENETIC ALGORITHM HEURISTIC IN MICROSOFT EXCEL}

Genetic algorithms (GAs) are one of the most popular heuristic algorithms that represent a powerful and robust approach for developing heuristic for complex and large-scale combinatorial optimization problems. A GA can be described as a probabilistic search, which imitates the process of natural selection and evolution to evolve a population of initial solutions. Each solution of a problem is treated as an individual, whose fitness is governed by the corresponding objective function value and some penalization to infeasibility. Pairs of individuals of a given population are selected to act as parents and reproduce to generate the next population of better individuals through a structured yet randomized information exchange known as crossover operator. Diversity is added to the population by randomly changing some genes (mutation operator). As new offspring are generated, unfit individuals in the population are replaced using the concept of survival of the fittest. This evaluationselection-reproduction cycle is repeated until a satisfactory solution is found or other stopping criteria are met (Claudio B. Cunha, 2004).

GAs can be implemented in a variety of ways. The excellent books by (Goldberg, 1989; Davis, 1991 and Holland, 1975) describe many possible variants of GAs. We also refer to these books for various GA definitions and notations as chromosomes, alleles, genes, reproduction, etc., as well as for other problem specific operators.

In many problems with sufficient complexity, GAs may have a tendency to converge towards local optima rather than the global optimum of the problem. The likelihood of this occurring depends on the shape of the fitness landscape: Certain problems may provide an 


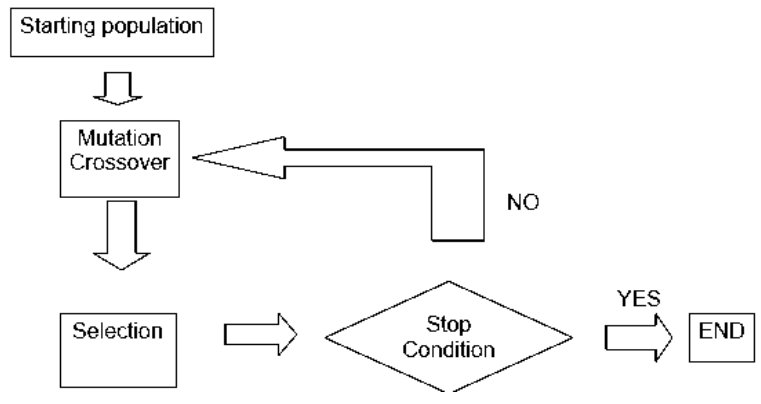

Fig. 2: Genetic algorithm cycle

easy ascent towards a global optimum, others may make it easier for the function to find the local optimums. This problem may be alleviated by using a different fitness function, or by using techniques to maintain a diverse population of solutions (Fig. 2).

- From old method generate an initial population of randomly constructed solutions. Each of the solutions is generated so that a bit position in a given string can become a transfer station take the value 1 , with a given probability $\mathrm{p}$ greater than zero; we adopted $\mathrm{p}=0.15$ based on preliminary experiments undertaken

- Select two parent solutions for reproduction. Some different methods were tried. We chose to use the binary tournament selection method, since it provided the best results in terms of speed, requiring less number of iterations to converge to the best solutions, according to some preliminary experiments undertaken. In this method, two individuals are chosen randomly from the population. The fitter (smaller fitness value) individual is then allocated a reproductive trial. In order to produce a child, two binary tournaments are held, each one producing one parent

- Generate a child solution by first applying a crossover operator to the selected parents. We use a single two-point crossover operator, in which two crossover points p $2 \quad\left\{1, \ldots, \quad \mathrm{N}_{-} 1\right\}$ and $\mathrm{q} 2$ $\{p+1, \ldots, N\}$ are selected and the child solution will consist of the first $p$ genes taken from the first parent, the next (q_p) genes taken from the second parent and the remaining $\left(\mathrm{jNj} \_\mathrm{q}\right)$ genes taken from the first parent, or vice-versa with equal probabilities. The crossover procedure is followed by a mutation procedure. Each bit in the offspring can be mutated (changed from 0 to 1 or vice versa) with some low probability

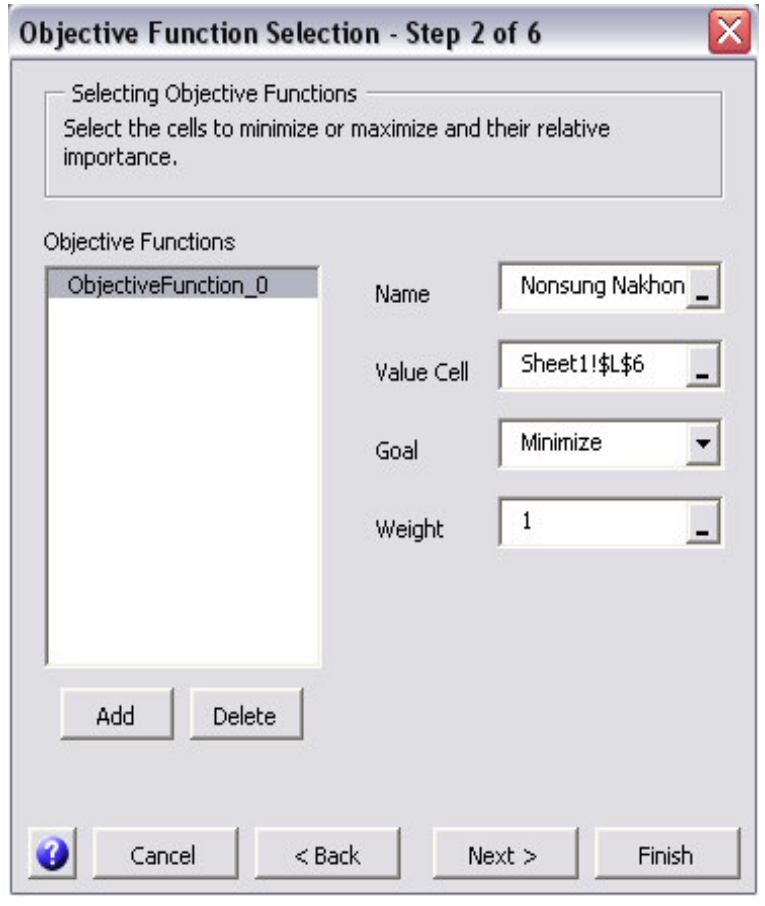

Fig. 3: Objective Function Selection Step 2 of 6

- For each generated offspring solution, determine the initial assignment of the transfer station to the corresponding nearest disposal site and then calculate the fitness, taking into consideration the flows between hubs to determine the proper discount factor

- Apply a local search heuristic to each generated individual in order to improve the assignment of the transfer station to the disposal site

- Evaluate the new population and replace an individual in the solution by the child solution. We use an elitist generation replacement,in which only the $\mathrm{n}$ best individuals ( $\mathrm{n}$ is the population size) are taken into the next generation

- Steps 2-6 are repeated until a pre-defined number of iterations is reached

This research use Optworks 1.2 solve the genetic algorithms (GAs) in microsoft excel have automatic setup of mutation, crossover, selection and probabilities as follows,

Figure 3 shows the step in variable insertion will begin at value specification.Objective function of the model which there is work format that resemble with solver of Microsoft Excel. 


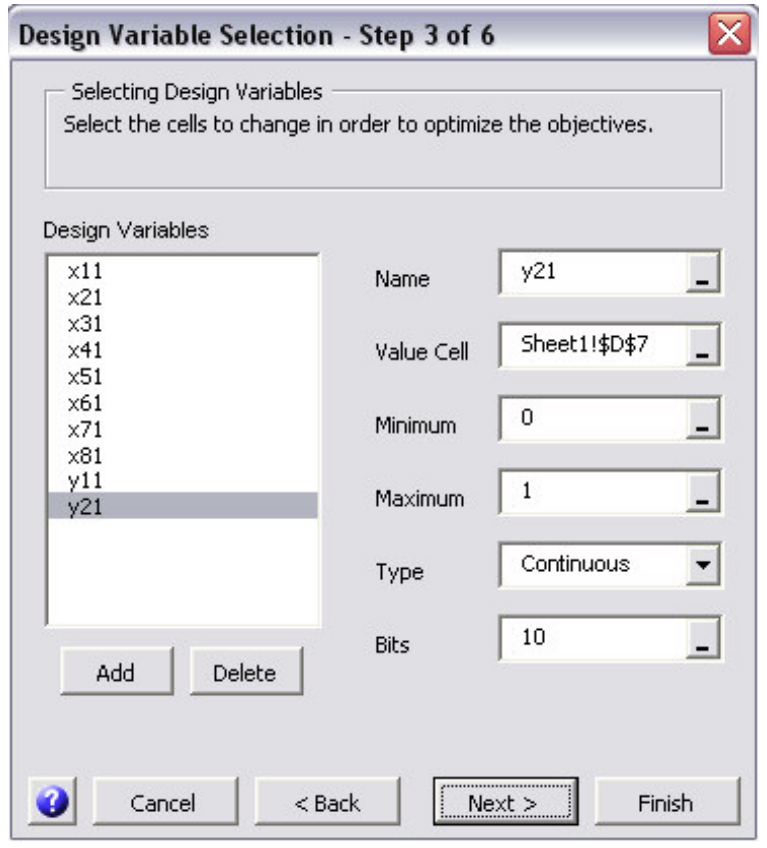

Fig. 4: Design Variable Selection Step 3 of 6

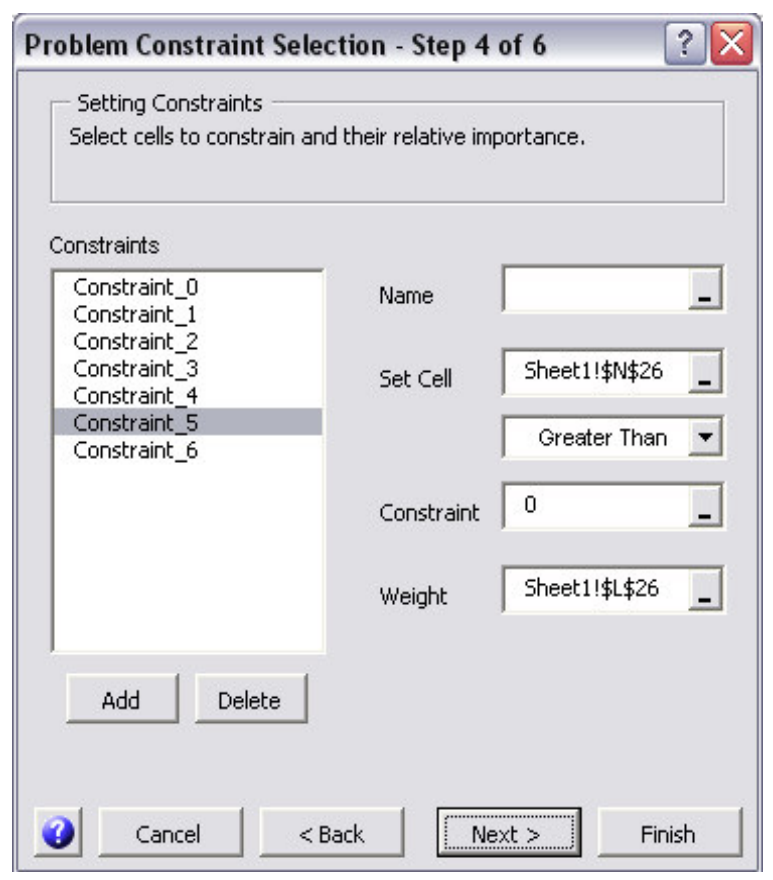

Fig. 5: Problem Constraint Selection Step 4 of 6

Figure 4 shows the specification given name step changes that want to seek the value.

Figure 5 shows the value specification constraints be building limitation all of the model.

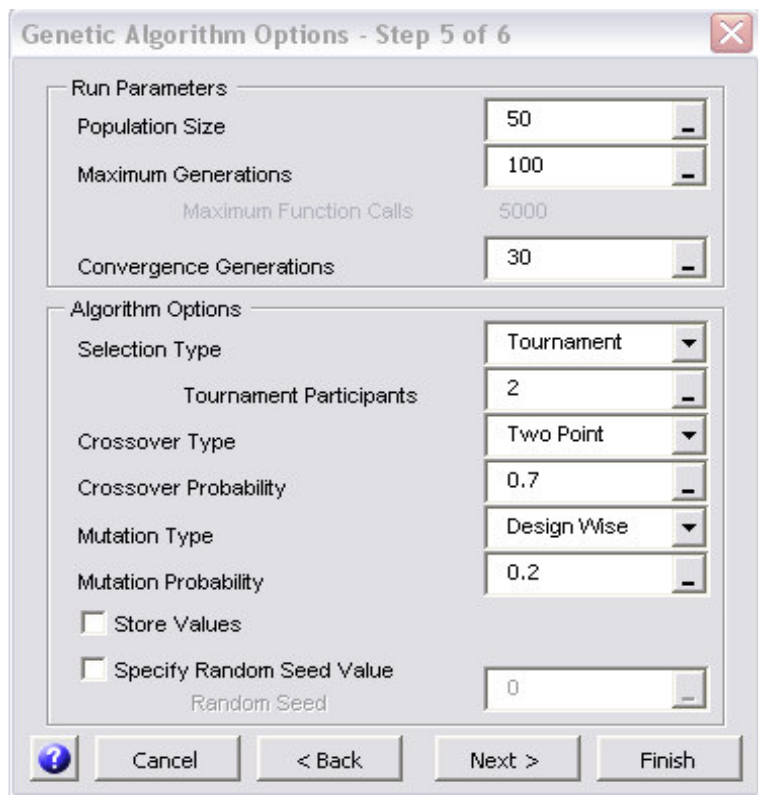

Fig. 6: Genetic Algorithm Options Step 5 of 6

Figure 6 shows the value specification of genetic algorithm a program will do the specification automatically but if want to fine repair the value differs as a result can do.

\section{CONCLUSIONS}

A building model for seek expenses in garbage shipping from the source goes to the disposal site and use the remedy with the way Genetic Algorithm, for seek cost minimum transport and garbage quantity in Nonsung District Nakhon Ratchasima Province consider 8 garbage sources there is garbage quantity happens altogether is 20 tons/day the station transfers 7 tons/day size capacity garbages and the place capacity 25 tons/day size capacity garbages from the remedy with GA meet that all cost in garbage shipping from garbage source goes to the disposal site by think the value manages of the station transfers the garbage, cause 5634.45 Bath/day minimum cost which can reduce the cost from originally 6785.23 Bath/day at born from the shipping that still no plan.

\section{ACKNOWLEDGEMENTS}

The authors thank Assoc. Prof. Samphan Littidej and Asst. Prof. Somprasong Suttayamully for idea of transforming the problem into a minimum cost of transport gabage and the referees for their helpful comments. 


\section{REFERENCES}

1. Chan, K.C. and H. Tansri, 1994. A study of genetic crossover operations on the facilitieslayout problem. Comput. Ind. Eng., 26 (3): 537-550.

2. Goldberg, D.E., 1989. Genetic Algorithms: In Search, Optimization and Machine Learning. New York: Addison-Wesley Publishing Co. Inc.

3. O'Kelly, M.E., 1986. The location of interacting hub facilities, Transport. Sci., 24: 92-106.

4. Park, J. and T.W. Simpson, 2005. Development of a production cost estimation framework to support product family design. Int. J. Prod. Res., 43 (4): 731-772.
5. Skorin-Kapov, D., J. Skorin-Kapov and M.E. O'Kelly, 1996. Tight linear programming relaxations of uncapacitated p-hub median problems. Eur. J. Operat. Res., 94: 582-593.

6. Thamnamsin, S., 2004. Development of Computer Software for Minimizing Cost of Hauling Solid Waste from Source to Disposal Site. MSE Thesis. Environmental Engineering, Graduate School, Khon Kaen University.

7. Wacker, J.G. and M. Trelevan, 1986. Component part standardization: An analysis of commonality sources and indices. J. Operat. Manage., 6 (2): 219-2448. 